\title{
Trends in paediatric practice in Australia: 2008 and 2013 national audits from the
}

\section{Australian Paediatric Research Network}

Authors: Harriet Hiscock ${ }^{1,2,3}$, Margie H Danchin ${ }^{1,2,3}$, Daryl Efron ${ }^{1,2,3}$, Alisha Gulenc ${ }^{2}$, Stephen Hearps ${ }^{2}$, Gary L Freed ${ }^{4,5}$, Prescilla Perera ${ }^{2}$, Melissa Wake ${ }^{1,2,3}$.

\section{Affiliations}

${ }^{1}$ The Royal Children's Hospital, Melbourne, AUSTRALIA

${ }^{2}$ Murdoch Childrens Research Institute, Melbourne, AUSTRALIA

${ }^{3}$ Department of Paediatrics, The University of Melbourne, Melbourne, AUSTRALIA.

${ }^{4}$ School of Population and Global Health, The University of Melbourne, Parkville, AUSTRALIA

${ }^{5}$ Child Health Evaluation and Research Unit, University of Michigan, Ann Arbor, MI, USA.

Corresponding author: A/Prof Harriet Hiscock, Centre for Community Child Health, Royal Children's Hospital Melbourne, Flemington Road, Parkville, Victoria AUSTRALIA 3052. Ph: +6139345 6910, Fx: +6139345 5900, Email: harriet.hiscock@rch.org.au

Word count: 2496

Key words: children, audit, paediatrician, developmental-behavioural

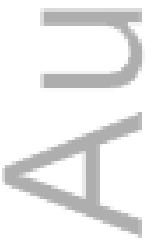

This is the author manuscript accepted for publication and has undergone full peer review but has not been through the copyediting, typesetting, pagination and proofreading process, which may lead to differences between this version and the Version of Record. Please cite this article as doi: $10.1111 /$ jpc. 13280

This article is protected by copyright. All rights reserved. 


\begin{abstract}
Aim: In adult medicine, rates of investigation and prescribing appear to be increasing. Such information is lacking for paediatrics. We audited Australian paediatricians' practices in 2013 to determine changes since 2008 in (i) conditions seen; (ii) consultation duration; (iii) imaging and pathology ordered; and (iv) prescribing.
\end{abstract}

Methods:-Patient-level prospective audit of paediatricians' secondary care practice. In November-December 2013, members of the Australian Paediatric Research Network were invited to complete standardised forms for 100 consecutive patients or all patients seen over two weeks, whichever was completed first. Main measures: Diagnoses, consultation duration, pathology and/or imaging investigations ordered, rate of medication prescription. Analyses: Hierarchical linear modelling clustered at the paediatrician level.

Results: 180 paediatricians (48\% of those eligible) contributed 7,102 consultations. The proportion of developmental/behavioural conditions rose from $48 \%$ (SD 31\%) to $60 \%$ (SD $30 \%$ ) in new and 54\% (SD 28\%) to 66\% (SD 28\%) in review consultations in 2013 compared with 2008. More paediatricians reported diagnoses of autism spectrum disorder ( $39 \%$ to $56 \%$, $\mathrm{p}=0.002)$, attention-deficit/hyperactivity disorder $(47 \%$ to $55 \%, \mathrm{p}=0.05)$, and intellectual disability $(18 \%$ to $36 \%, \mathrm{p}=0.001)$ in first consultations. Mean consultation duration and pathology/imaging ordering rates were stable. Prescribing rates increased from $39 \%$ to $45 \%$ of consultations for the top 10 new diagnoses, and from $57 \%$ to $68 \%$ of consultations for the top 10 review diagnoses.

This article is protected by copyright. All rights reserved. 
Conclusions: Paediatricians are seeing more children with developmental-behavioural conditions, prescribing more, and demonstrating wide variation in their practice. The latter suggests both over- and under-treatment.

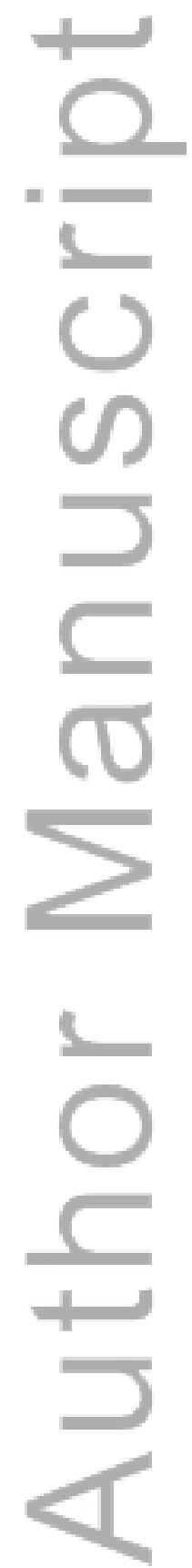

This article is protected by copyright. All rights reserved. 


\section{INTRODUCTION}

In adult medicine, delivery of many health care practices has increased in recent years. Some of these are clearly beneficial, reflecting either treatment advances such as combination therapy for $\mathrm{HIV}^{1}$ or the use of genomic testing to direct more specific cancer therapy. ${ }^{2}$ However, other widely-implemented activities are costly, of uncertain benefit and may even be harmful including screening activities (eg for prostate cancer), imaging (eg for back pain) and prescribing (eg for mild hypertension).

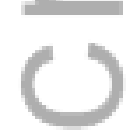

Like adults, today's children live in a world where the epidemiology of health and disease continues to evolve, and where the choices regarding care that could be provided are greater than ever before. On the one hand, the incidence of some conditions has clearly risen in recent years (eg diabetes, food allergy), and for others new evidence from rigorous trials has clearly demonstrated benefits from medication (eg stimulants for core symptoms of attention deficit hyperactivity disorder, ${ }^{3}$ selective serotonin reuptake inhibitors for moderate/severe anxiety). ${ }^{4}$ In these instances, an increase in prescribing might be seen as appropriate. On the other hand, children's healthcare is as open as that of adults to over-diagnosis (when a true abnormality is discovered, but detection of that abnormality does not benefit the patient) and overtreatment/overuse (when excess medication or procedures are provided to patients for both correct and incorrect diagnoses). ${ }^{5}$ Many problems, such as learning problems, autism spectrum disorders and mental health disorders, may also be open to 'diagnosis creep', where less well defined difficulties that might in earlier decades have been considered normal are increasingly coming to medical attention. 
Before issues of 'too much medicine' or 'too little medicine' can be addressed in paediatric practice, it is necessary to know 'how much medicine' is occurring. Yet such evidence is scant. For example, while Australian national data are collected on medications dispensed and investigations ordered by doctors, diagnostic data are not linked to these practices. Therefore, it is impossible to say whether a particular practice represents optimal care. As a starting point, it is vital to document the evolution of current practice, specifically secular trends in diagnosis, investigation and management. One way of doing this is via national practice audits of care. Ideally, these would bring together all of the necessary information diagnoses, treatments and investigations - into a single whole-of-practice framework.

In Australia, general paediatricians provide care to children and adolescents, predominantly in secondary care settings including private practices, hospital outpatient clinics, and community health centres. To be seen by a general paediatrician, children must be referred by a general practitioner which allows families to receive a Medicare (financial) rebate for the consultation. ${ }^{6}$ In 2008, we conducted the first national audit of general and community paediatric practice. We found that developmental and behavioural conditions accounted for the bulk of the general paediatric casemix. ${ }^{7}$ We repeated this audit in 2013 . This paper reports diagnoses and management practices and compares them with those reported in 2008. We hypothesised that, compared to 2008, paediatricians in 2013 would report: (i) an increase in the proportion of consultations for developmental and behavioural conditions; (ii) a decrease in time spent per consultation; (iii) an increase in imaging and pathology testing; and (iv) an increase in prescription of medications. 


\section{METHODS}

This was a prospective clinical audit of general paediatricians' outpatient practice in public hospital outpatient clinics, community health centres and private rooms.

All members of the Australian Paediatric Research Network (APRN), a national, practicebased, secondary care research network, were invited via email to take part in October 2013. Audit booklets were mailed to eligible and interested paediatricians. Paediatricians were asked to complete a data form for each patient seen over a two week period from November $18^{\text {th }}$ to December $2^{\text {nd }} 2013$, or for 100 consecutive patients, whichever came first. Paediatricians mailed completed booklets back to the research team.

\section{Measures}

To report change over time, the data collection form (Figure 1) replicated the 2008 form. ${ }^{7}$ This was modelled on the form used by Bettering the Evaluation and Care of Health $(\mathrm{BEACH})$. BEACH has for many years conducted an annual audit of a national random sample of Australian general practitioners. ${ }^{8}$ The form included the consultation date, start and end times; practice setting; family and paediatrician practice postcode, language spoken at home, the child's height and weight; diagnoses made; investigations ordered; medications prescribed (including over the counter medications such as vitamins); vaccines administered; referrals made; and Medicare consultation items numbers billed encompassing simple (ie one condition) and complex (ie two or more conditions) new and review consultation item numbers. 
A list of the 60 most common diagnostic codes, replicating the 2008 audit, was provided on the back of each consultation form. Paediatricians could either write the code corresponding to a diagnosis or write the diagnosis if it was not on the list. Each booklet comprised 100 data collection forms and instructions on how to complete the booklet.

All completed booklets were hand cleaned and then scanned and verified using Cardiff Teleform 10.2 software by the research team. Members of the APRN steering committee (HH, MW, DE, MD, and GR) assigned codes and cross-checked the 56 diagnoses recorded in addition to the 60 most common diagnoses (ie total of 116 diagnoses coded). Paediatrician practice postcodes were used to calculate census derived Socio-Economic Indexes for Areas (SEIFA) index for relative social disadvantage (national mean of 1000, standard deviation of 100). ${ }^{9}$ Lower scores reflect greater disadvantage.

Ethics approval was granted by The Royal Children's Hospital Human Research Ethics Committee (HREC \#33197).

\section{Statistical analyses}

To determine nation-wide generalisability, demographic and practice characteristics of APRN member responders were compared with characteristics of APRN member non-responders and Australian general paediatricians, based on the 2013 Australian Health Practitioner Regulation Agency workforce survey (completed by around 96\% of medical specialists). Characteristics of children seen were calculated as means and standard deviations (eg for age) and proportions (eg for gender, number of comorbidities). Consultations were categorised as “new" or "review" based on Medicare billing coding. 
To compare data from 2008 and 2013, we used multi-level models (random effect regression), ${ }^{10}$ which allowed for analysis of all paediatricians, regardless of participation in both 2008 and 2013 waves. We clustered consultations at the paediatrician level (Level 2), allowing for repeated measurement of consultations (Level 1) within paediatrician as well as over time. Medication, consult and paediatrician rate within diagnosis models were clustered at the paediatrician level only. We examined whether there was evidence of change over time in any of our outcomes of interest (types of consultations, time spent per consultation, use of imaging and pathology investigations, prescription of medication). All analyses were performed using Stata version 13.1. ${ }^{11}$

\section{RESULTS}

Of the 451 APRN members, 75 (17\%) were ineligible (eg on leave, illness, uncontactable, retired), and 180 of the remaining 376 (48\%) participated. Paediatricians working in the state of Victoria were over represented, while those working in New South Wales, South Australia, Tasmania and the Northern Territory were under represented relative to the national distribution of paediatricians. ${ }^{12}$ Compared with general paediatricians across Australia, responders were more likely to be female, younger, and working part time (Table 1).

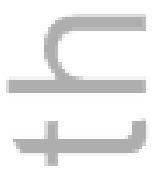

Paediatricians collected data on 7102 consultations over the two week period. Children were seen at practices from a broad socioeconomic range (SEIFA mean 1000.4, SD 69.6). Most children seen were male (57\%), with a mean age of 7.6 years (standard deviation 5.6 years). 
The proportion of children diagnosed with 1,2 , and 3 or more conditions was $35.1 \%, 32.7 \%$ and $31.8 \%$, respectively (Table 2 ).

Similar to 2008, the majority of 2013 consultations were for developmental and behavioural problems but the proportion of consultations including such conditions increased across both new and review consultations from 2008 to 2013 (see Table 3). Overall, developmental and behavioural problems rose from $48 \%$ (SD 31\%) to $60 \%$ (SD 30\%) of paediatricians' new consultations, and from 54\% (SD 28\%) to 66\% (SD 28\%) of review consultations (both $\mathrm{p}<0.001)$. In 2013, autism spectrum disorders were the most common new diagnosis $(15 \%$ in 2013, versus 5\% in 2008) and more paediatricians reported making this diagnosis in 2013 than in 2008 (56\% versus 39\%). A similar pattern was seen in review diagnoses. Attentiondeficit/hyperactivity disorder not only remained the most common condition managed by paediatricians overall, but increased as a diagnosis in both new and review consultations (from $10 \%$ to $14 \%$ and from $22 \%$ to $28 \%$, respectively). Anxiety, sleep problems and intellectual disability (IQ < 70) were all more likely to be diagnosed in 2013 compared with 2008. Consultation length changed little between 2008 and 2013 for either new or review consultations.

In both 2008 and 2013 imaging was ordered in fewer than $6 \%$ of consultations, with no change between the two audits. Similarly, the rate of pathology orders was unchanged (new, $14.8 \%$ in 2008 and $15 \%$ in 2013; review, $6 \%$ in both 2008 and 2013).

The prescribing of medications including over the counter products increased over this time for almost all common conditions, falling slightly in only one of the top 10 new conditions 
(language delay) and one of the top 10 review conditions (well baby check). Increases in prescribing rates were particularly marked for autism ( $28 \%$ of new diagnoses in $2008,42 \%$ in $2013, p=0.04)$, anxiety ( $59 \%$ to $74 \%$ for review diagnoses, $p=0.008)$, sleep disturbance $(29 \%$ to $52 \%$ for new diagnoses, $\mathrm{p}=0.003$ ), behaviour ( $53 \%$ to $65 \%$ for review diagnoses, $\mathrm{p}=0.04$ ), constipation ( $75 \%$ to $89 \%$ for review diagnoses, $\mathrm{p}=0.006)$, and asthma $(75 \%$ to $86 \%$ for new diagnoses, $p=0.007$ ) (Table 3). There were large standard deviations in mean rates of prescribing across all conditions, indicating wide inter-paediatrician variation. We found a similar pattern of changes when we restricted our sample to the 113 paediatricians who competed the audit at both time points (Table 4).

\section{DISCUSSION}

In the five year period 2008-2013, consultations for developmental and behavioural problems rose to become an even higher proportion of Australian general / community paediatric practice. Unlike the stability seen in mean consultation duration and rates of imaging and pathology investigations, prescribing rates rose markedly across virtually every condition and for both new and review consultations.

Strengths and limitations: This study has a number of strengths. It is the only Australian audit of paediatric practice in non-acute settings and used an established data collection method. ${ }^{8}$ It collected rich data over two time points, with the same $113(42 \%)$ APRN paediatricians participating both times. We could find no comparable international audits of paediatric speciality care. 
Among the study's limitations are that only around half of the eligible APRN members took part, and those that did were more likely to be female, younger and working part time than Australian general paediatricians overall. As such our results may not generalise to male or older paediatricians or those working full time. However, our 2008 audit showed no evidence of developmental-behavioural caseload differences by paediatrician gender. ${ }^{7}$ Even though collected prospectively and in real time, our audit relied on reported and not actual practice. Use of electronic records may be considered more valid, but still relies on accurate input of data and is not a viable option given that only 50\% of Australian paediatricians use electronic medical records. ${ }^{13}$ While we reported medications prescribed by the child's first listed diagnosis, many children had more than one diagnosis and so the medication may have been for a comorbid diagnosis. Paediatricians were more likely to record seeing a child with three or more diagnoses in $2013(32 \%)$ compared with $2008(23 \%)$ and this may explain some of the increase in prescribing.

Interpretation of findings: There are many possible reasons why a much higher proportion of paediatric outpatient practice now involves developmental and behavioural problems; some or all may co-exist, and none can be confirmed by this or other published studies. 'Too much medicine' is one possibility, and could be supported by the increasing proportion of children being diagnosed with less categorical conditions such as anxiety and sleep problems from 2008 to 2013 . However, this rise could equally represent: (1) a greater availability of private paediatric services, (2) increased parental awareness and hence presentation to general practitioners (the gateway to paediatric referral), (3) the rising proportion of longer general 
practice consultations now given over to diseases of ageing, thus squeezing out children, ${ }^{14}$ and/or (4) changes in funding and remunerative structures. For example, the recent provision of Australian government funding (\$AUS 12,000 per child) for early intervention services for certain conditions has almost certainly prompted families to attend paediatricians for a diagnosis; however, this funding does not apply to other conditions where diagnoses as a proportion of consultations have also increased. Whatever the reason, these increases could be "good"; for example, recent data from a Swedish population-based study indicate that autism diagnosis is now approaching the population prevalence of the autism phenotype. ${ }^{15}$ On the other hand, these increases could be "bad", if they represent over-diagnosis of children with milder difficulties who are less likely to benefit, and may even experience resulting harm.

Similarly, the marked rise in prescribing could represent overtreatment and/or better implementation of existing treatments and availability of new ones. For example, melatonin has been shown in a controlled trial to improve sleep onset in children with neurodevelopmental disabilities, ${ }^{16}$ and its availability through compounding pharmacies has led to rapid uptake by Australian paediatricians. ${ }^{17}$ On the other hand, there is good evidence that brief (ie 2-3 sessions) non-pharmacological interventions are effective in reducing sleep problems including sleep onset delay in children without neurodevelopmental disorders ${ }^{18,19}$ as well as those with attention deficit disorder. ${ }^{20}$ The potential factors underlying the rising use of medication for anxiety are less clear. While non-pharmacological interventions such as cognitive behavioural therapy (CBT) are effective in treating anxiety ${ }^{21}$ their intensity (typically requiring 10 sessions or more ${ }^{21}$ ), cost and lack of availability may make medication 
a practical alternative. Furthermore, children may have already received non-pharmacological therapy at the time of their first consultation with the paediatrician. For more severe anxiety, the synergistic use of CBT and medications such as sertraline is more effective than either therapy alone and therefore use of medication may reflect appropriate management. ${ }^{22}$

Whatever the appropriateness of medication for different conditions, the marked interpaediatrician variation evidenced by the large standard deviations suggests that both overand under-treatment are common. Large variation has also been reported in hospitalists' management of common child health conditions in the USA, even for therapies with a proven evidence-base. ${ }^{23}$ Similarly, a review of practice variation for 16 common child conditions found that unwarranted variation in care, largely reflecting over-treatment, was widespread across conditions and health sectors. ${ }^{24}$

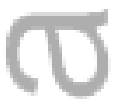

Paediatricians are seeing more children with developmental-behavioural conditions, prescribing more, and demonstrating wide variation in their practice. Whether paediatricians are over diagnosing and over-treating conditions requires further research to establish whether making these diagnoses leads to better outcomes for children and families. ${ }^{5}$ Ideally this would involve prospective, routine data collection of paediatricians' diagnosis, investigations, and treatment, at a population level, with a marker of severity of conditions. Further research into systems (eg access to services), patient (eg costs and family preferences) and paediatrician-level (eg knowledge and training) factors driving paediatricians' practices is also needed. 


\section{ACKNOWLEDGEMENTS}

We thank the paediatricians for taking part in the study.

Contributor's Statement: HH, MD, DE, GF and MW made substantial contributions to the conception and design of the study. AG acquired the data. SH and $\mathrm{AG}$ analyzed the data. $\mathrm{HH}$, MD, DE, GF, SH and MW interpreted the data. HH drafted the manuscript. MW, MD, DE, GF, SH, PP, and AG critically reviewed the article for important intellectual content. All authors gave final approval of the version to be published. All authors had full access to all the data (including statistical reports and tables) in the study and can take responsibility for the integrity of the data and the accuracy of the data analysis. $\mathrm{HH}$ is the guarantor.

Funding: The study was supported by a Royal Australasian College of Physicians (RACP) Fellowship Award. HH's position is funded by an Australian National Health and Medical Research Council career development award (No 607351). MW's position is funded by an Australian National Health and Medical Research Council Senior Research fellowship (No 1046518). Murdoch Childrens Research Institute is supported by the Victorian Government's operational infrastructure support programme. The RACP had no role in the study design, the collection, analysis, and interpretation of the data, the drafting of the manuscript, or the decision to submit this paper for publication. All researchers worked independently from the funder.

Competing interests: The authors have no competing interest to declare.

This article is protected by copyright. All rights reserved. 


\section{What is already known on this topic:}

- Rates of investigation and prescribing in adult medicine are known to be increasing however, such information is lacking for paediatrics.

- Analysis of information on diagnoses, investigations, and treatments - available in a single whole-of-practice framework - is needed in order to describe trends in paediatric medicine.

$=$

\section{What this study adds:}

- In a national, prospective audit of diagnoses, investigations, and treatments, Australian paediatricians report diagnosing more developmental and behavioural conditions and prescribing more medication over a 5 year period.

- Marked inter-paediatrician variation suggests both over- and under-treatment.

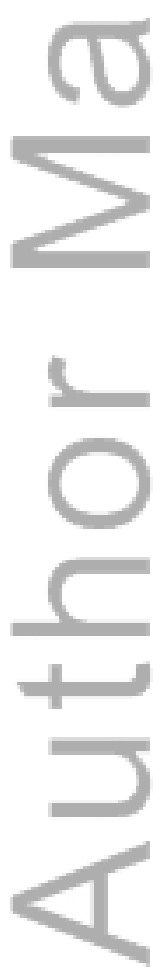




\section{REFERENCES}

1. Ray M, Logan R, Sterne JA, et al. The effect of combined antiretroviral therapy on the overall mortality of HIV-infected individuals. AIDS. 2010; 24:123-137

2. Dancey, J. E., Bedard, P. L., Onetto, N., \& Hudson, T. J. The genetic basis for cancer treatment decisions. Cell. 2012; 148; 3:409-420.

3. Attention-Deficit Subcommittee on "ADHD: clinical practice guideline for the diagnosis, evaluation, and treatment of attention-deficit/hyperactivity disorder in children and adolescents." Pediatrics. 2011; 128; 5: 1007-1022

4. Ipser JC, Stein DJ, Hawkridge S, et al. Pharmacotherapy for anxiety disorders in children and adolescents. Cochrane Database Syst Rev 2009;3(3):CD005170.

5. Coon, E. R., Quinonez, R. A., Moyer, V. A., \& Schroeder, A. R. Overdiagnosis: how our compulsion for diagnosis may be harming children. Pediatrics. 2014; 134; 5:1013-1023.

6. Australian Government Department of Human Services. Medicare: for individuals. Available at http://www.medicareaustralia.gov.au/public/index.jsp. Accessed March 15th, 2015.

7. Hiscock H, Roberts G, Efron D, Sewell J, Bryson H, Price A, Oberklaid F, South M, Wake M. Children Attending Paediatricians Study: a national prospective audit of outpatient practice from the Australian Paediatric Research Network. Med J Aust. 2011;194; 8:392-397.

8. Britt HC, Miller GC. The BEACH study of general practice [editorial]. Med J Aust. 2000; 173: 63-64.

9. Australian Bureau of Statistics. Census of Population and Housing: Socio-Economic Indexes for Areas (SEIFA), Australia - Data only Canberra: Author.

http://www.abs.gov.au/AUSSTATS/abs@.nsf/DetailsPage/2033.0.55.0012011?OpenDocume nt. Published 2013.

10. Hedeker D, Gibbons RD: Application of random-effects pattern-mixture models for missing data in longitudinal studies. Psychological Methods. 1997; 2 ;1:64-78.

11. StataCorp. 2013. Stata Statistical Software: Release 13. College Station, TX: StataCorp LP.

12. Health Workforce Australia National Health Workforce Dataset. [Accessed March 15th 2016]. Available from: https://www.hwa.gov.au/resources/health-workforce-data

13. Wake M, Davies S, Hiscock H, Chaney G. E-health in Australia: time to plunge into the 21st century. [Letter to the Editor.] Med J Aust. 2011; 194;4:211-212. 
14. Freed, G.L., J.R. Sewell, and N.A. Spike, Challenges to children's healthcare in an ageing Australia. Med J Aust. 2011. 195;8: 436-437.

15. Lundström, S., Reichenberg, A., Anckarsäter, H., Lichtenstein, P., \& Gillberg, C. Autism phenotype versus registered diagnosis in Swedish children: prevalence trends over 10 years in general population samples. BMJ. 2015. 350:h1961

16. Gringras P, Gamble C, Jones AP, Wiggs L, Williamson PR, Sutcliffe A, Montgomery P, Whitehouse WP, Choonara I, Allport T, Edmond A, Appleton R; MENDS Study Group. Melatonin for sleep problems in children with neurodevelopmental disorders: randomised double masked placebo controlled trial. BMJ. 2012 5;345:e6664.

17. Heussler H, Chan P, Price A, Waters K, Davey M, Hiscock H. Pharmacological and nonpharmacological management of sleep disturbance in children: an Australian Paediatric Research Network survey. Sleep Medicine. 2013; 14; 2:189-194

18. Quach J, Hiscock H, Ukoumunne OC, Wake M. A brief sleep intervention improves outcomes in the school entry year: a randomized controlled trial. Pediatrics 2011;128;4:692701.

19. Meltzer, Lisa J., and Jodi A. Mindell. "Systematic review and meta-analysis of behavioral interventions for pediatric insomnia." Journal of Pediatric Psychology. 2014. 39.8: 932-948.

20. Hiscock H, Sciberras E, Mensah F, Gerner B, Efron D, Khano S, Oberklaid F. Impact of a behavioural sleep intervention on symptoms and sleep in children with attention deficit hyperactivity disorder, and parental mental health: randomised controlled trial. BMJ. 2015: h68.

21. James, A. C., James, G., Cowdrey, F. A., Soler, A., \& Choke, A. Cognitive behavioural therapy for anxiety disorders in children and adolescents. Cochrane Database Syst Rev. 2013 6: CD004690.

22. Walkup, J. T., Albano, A. M., Piacentini, J., Birmaher, B., Compton, S. N., Sherrill, J. T., ... \& Kendall, P. C. Cognitive behavioral therapy, sertraline, or a combination in childhood anxiety. N. Engl. J. Med. 2008; 359; 26:2753-2766.

23. Landrigan, C. P., Conway, P. H., Stucky, E. R., Chiang, V. W., \& Ottolini, M. C. Variation in pediatric hospitalists' use of proven and unproven therapies: a study from the Pediatric Research in Inpatient Settings (PRIS) network. Journal of Hospital Medicine. 2008. 3;4: 292-298.

24. Hiscock, H., P. Perera, K. McLean, and G. Roberts, Variation in paediatric clinical practice Evidence Check Review brokered by the Sax Institute for the NSW Ministry of Health, 2014. Available from the Sax Institute website. [Accessed March 15th 2016] 


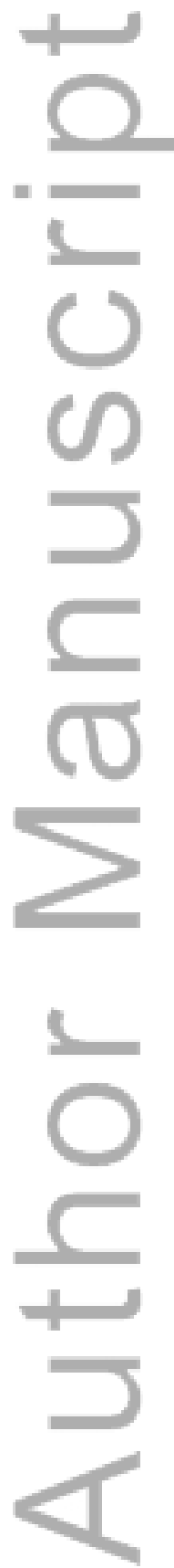

This article is protected by copyright. All rights reserved. 
Table 1: Comparison of Australian general paediatricians and responding and nonresponding APRN members.

$$
\mathbf{N}(\%)
$$

All paediatricians APRN responders $\quad$ APRN non-responders

\begin{tabular}{lcccccc} 
Characteristic & \multicolumn{2}{c}{$(\mathbf{n = 1 4 4 2})$} & \multicolumn{2}{c}{ (n=180) } & \\
\hline Male & 701 & $(48.6)$ & 82 & $(45.6)$ & 112 & $(57.1)$ \\
& & & & & & \\
Age (years) & 440 & $(30.5)$ & 71 & $(39.4)$ & 87 & $(44.4)$ \\
444 & 463 & $(32.1)$ & 60 & $(33.3)$ & 65 & $(33.2)$ \\
$55-64$ & 342 & $(23.7)$ & 31 & $(17.2)$ & 37 & $(18.9)$ \\
$65+$ & 146 & $(10.1)$ & 13 & $(7.2)$ & 2 & $(1.0)$
\end{tabular}

State

Australian Capital

$\begin{array}{lcccccc}\text { Territory } & 23 & (1.6) & 8 & (4.4) & 5 & (2.6) \\ \text { New South Wales } & 486 & (33.7) & 49 & (27.2) & 63 & (32.1) \\ \text { Northern Territory } & \text { n.p. } & - & 1 & (0.6) & 7 & (3.6) \\ \text { Queensland } & 270 & (18.7) & 27 & (15.0) & 32 & (16.3) \\ \text { South Australia } & 112 & (7.8) & 4 & (2.2) & 11 & (5.6) \\ \text { Tasmania } & \text { n.p. } & - & 3 & (1.7) & 3 & (1.5) \\ \text { Victoria } & 356 & (24.7) & 75 & (41.7) & 50 & (25.5) \\ \text { Western Australia } & 133 & (9.2) & 12 & (6.7) & 25 & (12.8)\end{array}$


Working hours*

$\begin{array}{lllllll}\text { Part-time } & 373 & (25.9) & 111 & (61.7) & 69 & (35.2) \\ \text { Full-time } & 837 & (58.0) & 50 & (27.8) & 16 & (8.2)\end{array}$

Practice location

$\begin{array}{lllllll}\text { Metropolitan } & 1182 & (82.0) & 128 & (71.1) & 145 & (74.0) \\ \text { Regional/Rural } & 216 & (15.0) & 49 & (27.2) & 38 & \text { (19.4) }\end{array}$

* Missing data due to poor response for item.

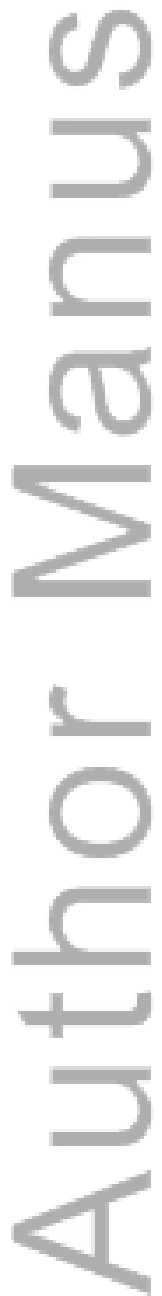

This article is protected by copyright. All rights reserved. 
Table 2. Patient characteristics in 2008 and 2013

\begin{tabular}{lccccc}
\hline Characteristic & \multicolumn{2}{c}{$\mathbf{2 0 0 8}$} & \multicolumn{2}{c}{$\mathbf{2 0 1 3}$} & p \\
& \multicolumn{2}{c}{$(\mathbf{n = 8 3 4 5 )}$} & \multicolumn{2}{c}{ (n=7102) } & \\
& 4796 & $(57.5)$ & 4019 & $(56.6)$ & 0.77 \\
\hline Male, n (\%) & 6.6 & $(5.5)$ & 7.6 & $(5.6)$ & $<0.001$ \\
Age (years), mean (SD) & 7333 & $(87.9)$ & 6705 & $(94.4)$ & $<0.001$ \\
English first language, n (\%) & 996.6 & $(75.8)$ & 1004.3 & $(69.6)$ & $<0.001$ \\
SEIFA, mean (SD) & & & & & $<0.001$ \\
Diagnosis & 3841 & $(46.0)$ & 2490 & $(35.1)$ & \\
1 & 2578 & $(30.9)$ & 2325 & $(32.7)$ & \\
2 or more & 1906 & $(22.8)$ & 2255 & $(31.8)$ & \\
\hline
\end{tabular}

This article is protected by copyright. All rights reserved. 
Table 3: 2013 top 10 ranked new and review consultations, comparing 2008 and 2013 outcomes.

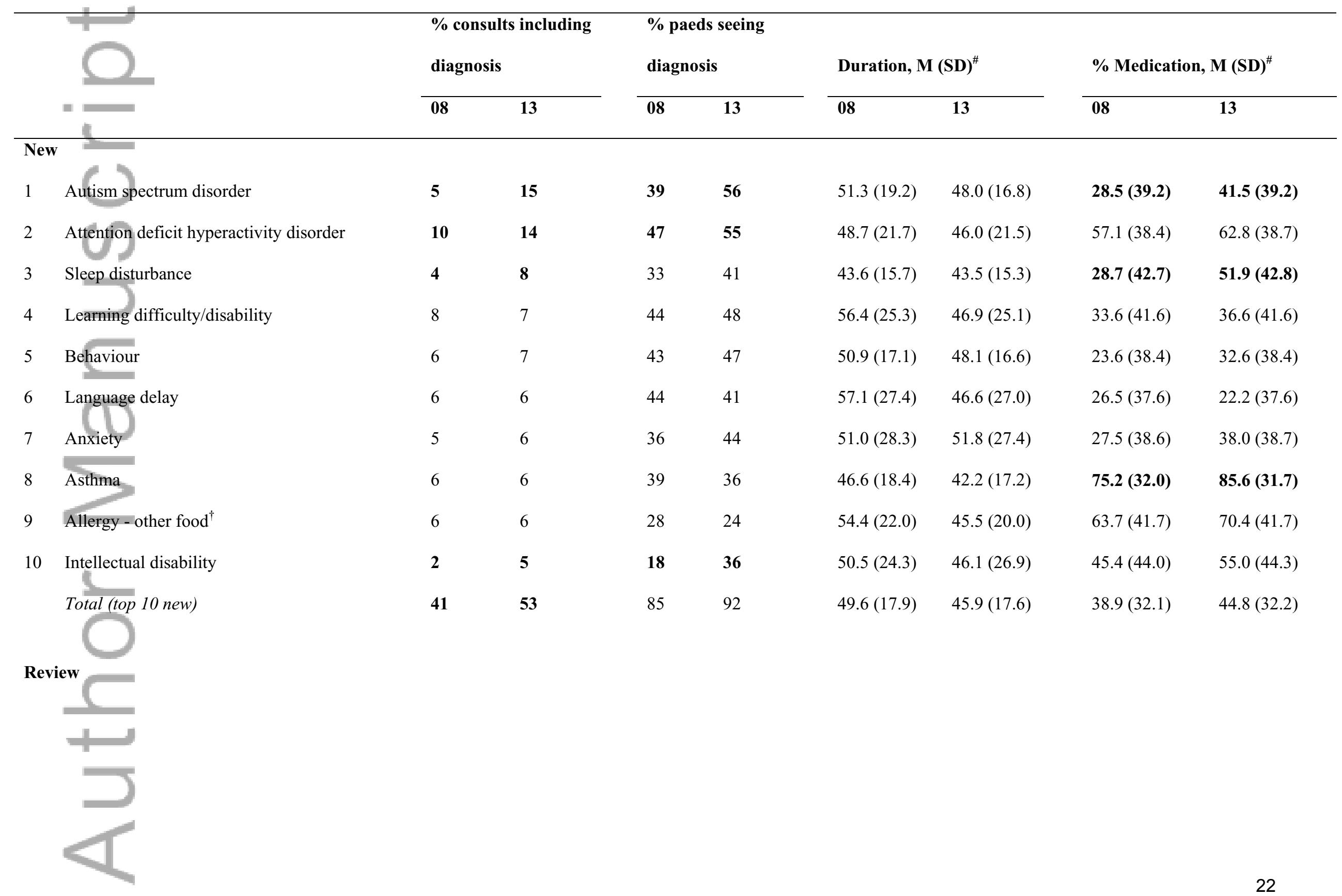

This article is protected by copyright. All rights reserved. 


\begin{tabular}{|c|c|c|c|c|c|c|c|c|c|}
\hline 1 & Attention deficit hyperactivity disorder & 22 & 28 & 68 & 74 & $25.5(12.1)$ & $26.6(11.9)$ & $87.4(21.0)$ & $88.2(21.0)$ \\
\hline 2 & Auntism spectrum disorder & 9 & 14 & 61 & 72 & $27.0(9.6)$ & $28.5(9.3)$ & $50.9(35.9)$ & $61.7(36.0)$ \\
\hline 3 & Learning difficulty/disability & 8 & 10 & 49 & 58 & $29.6(14.6)$ & $29.5(14.9)$ & $56.2(38.5)$ & $66.3(38.5)$ \\
\hline 4 & Baby check (premature/full-term) & 12 & 9 & 45 & 36 & $22.6(10.7)$ & $21.6(9.6)$ & $27.1(32.1)$ & $20.5(30.8)$ \\
\hline 5 & Anxiety & 4 & 8 & 43 & 56 & $30.7(20.7)$ & $31.2(20.8)$ & $58.5(37.7)$ & $73.6(37.7)$ \\
\hline 6 & Sleep disturbance & 3 & 7 & 33 & 53 & $26.9(14.9)$ & $32.3(14.0)$ & 50.4 (39.6) & $71.2(39.7)$ \\
\hline 7 & Asthma & 7 & 6 & 53 & 55 & $24.3(9.5)$ & $26.7(9.1)$ & $79.9(31.2)$ & $81.4(31.0)$ \\
\hline 8 & Behaviour & 5 & 6 & 55 & 56 & $28.7(13.1)$ & $29.7(12.3)$ & $52.6(41.3)$ & $64.7(41.3)$ \\
\hline 9 & Intellectual disability & 4 & 6 & 46 & 55 & $29.6(13.8)$ & $30.1(13.9)$ & $66.5(37.7)$ & $67.7(37.9)$ \\
\hline 10 & Constipation & 4 & 5 & 40 & 53 & $25.1(11.2)$ & $25.7(11.8)$ & $75.3(30.7)$ & $88.6(30.8)$ \\
\hline & Total (top 10 review) & 59 & 65 & 93 & 94 & $25.5(11.0)$ & $27.3(10.6)$ & $56.9(26.0)$ & $67.8(25.9)$ \\
\hline
\end{tabular}

*Bolded tests=significant $(p<0.05) .{ }^{\#}$ Estimated mean and SD from multi-level models. ${ }^{\dagger}$ Allergy to food other than cow's milk protein

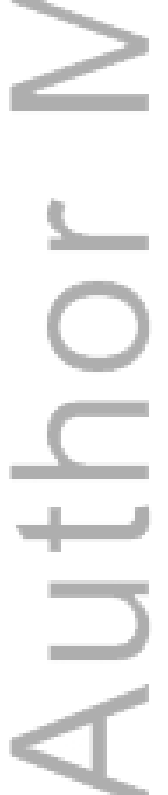


Table 4: CAPS 2013 top 10 ranked new and review consultations by the 113 paediatricians who completed 2008 and 2013 audits

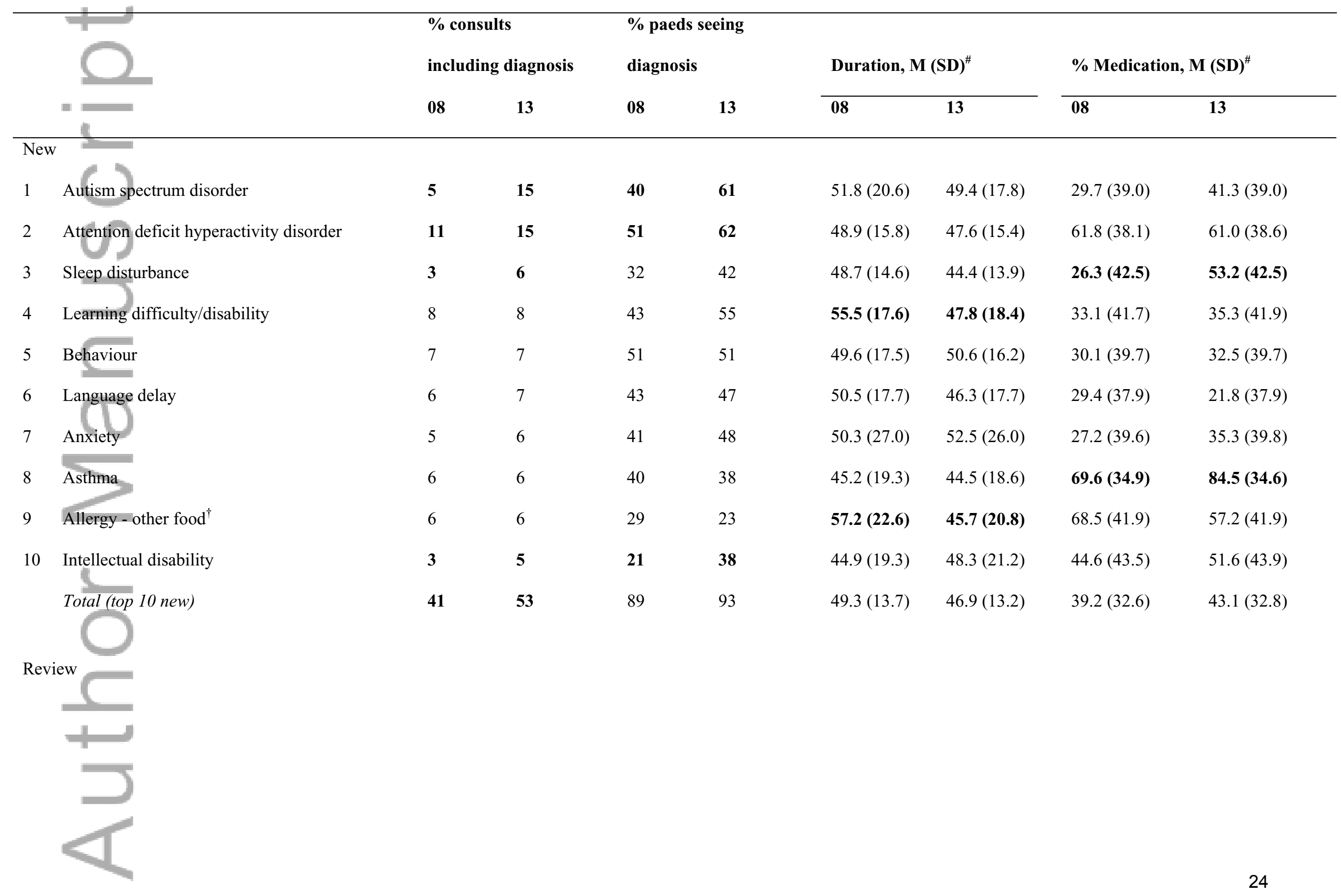

This article is protected by copyright. All rights reserved. 


\begin{tabular}{|c|c|c|c|c|c|c|c|c|c|}
\hline 1 & Attention deficit hyperactivity disorder & 21 & 30 & 65 & 75 & $24.8(10.4)$ & $26.9(10.6)$ & $84.4(21.4)$ & $89.2(21.4)$ \\
\hline 2 & Autism spectrum disorder & 8 & 14 & 63 & 74 & $26.9(10.1)$ & $29.1(9.9)$ & $52.4(36.0)$ & $61.9(36.2)$ \\
\hline 3 & Learning difficulty/disability & 8 & 11 & 50 & 62 & $27.8(9.8)$ & $28.4(10.3)$ & $56.9(38.8)$ & $62.7(39.0)$ \\
\hline 4 & Baby check (premature/full-term) & 12 & 10 & 48 & 39 & $22.0(7.1)$ & $20.0(6.8)$ & $27.0(31.9)$ & $19.7(31.0)$ \\
\hline 5 & Anxiety & 4 & 7 & 47 & 54 & $28.8(25.1)$ & $31.6(26.1)$ & $56.3(38.1)$ & $75.7(38.1)$ \\
\hline 6 & Sleep disturbance & 3 & 6 & 36 & 51 & $29.0(12.9)$ & $30.8(12.1)$ & $49.6(39.4)$ & $75.4(39.4)$ \\
\hline 7 & Asthma & 6 & 7 & 55 & 57 & $22.9(10.3)$ & $27.3(9.7)$ & $79.0(32.3)$ & $82.1(32.7)$ \\
\hline 8 & Behaviour & 4 & 7 & 51 & 59 & $29.0(11.5)$ & $30.0(11.1)$ & $47.2(41.6)$ & $63.1(41.6)$ \\
\hline 9 & Intellectual disability & 4 & 6 & 48 & 57 & $28.8(12.3)$ & $29.8(12.4)$ & $68.3(34.2)$ & $76.1(34.4)$ \\
\hline \multirow[t]{2}{*}{10} & Constipation & 5 & 5 & 43 & 54 & $25.6(10.9)$ & $25.6(11.8)$ & $78.9(29.7)$ & $87.8(29.7)$ \\
\hline & Total (top 10 review) & 58 & 68 & 94 & 94 & $24.9(9.5)$ & $26.9(9.4)$ & $56.8(25.7)$ & $68.4(25.8)$ \\
\hline
\end{tabular}

\footnotetext{
*Bolded tests $=$ significant $(\mathrm{p}<0.05)$
}

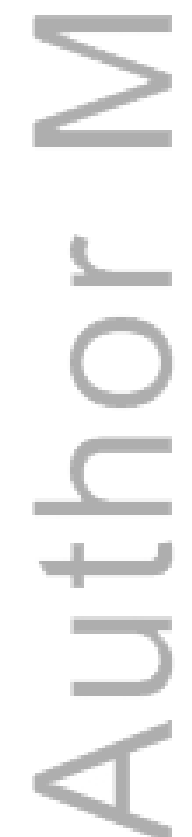




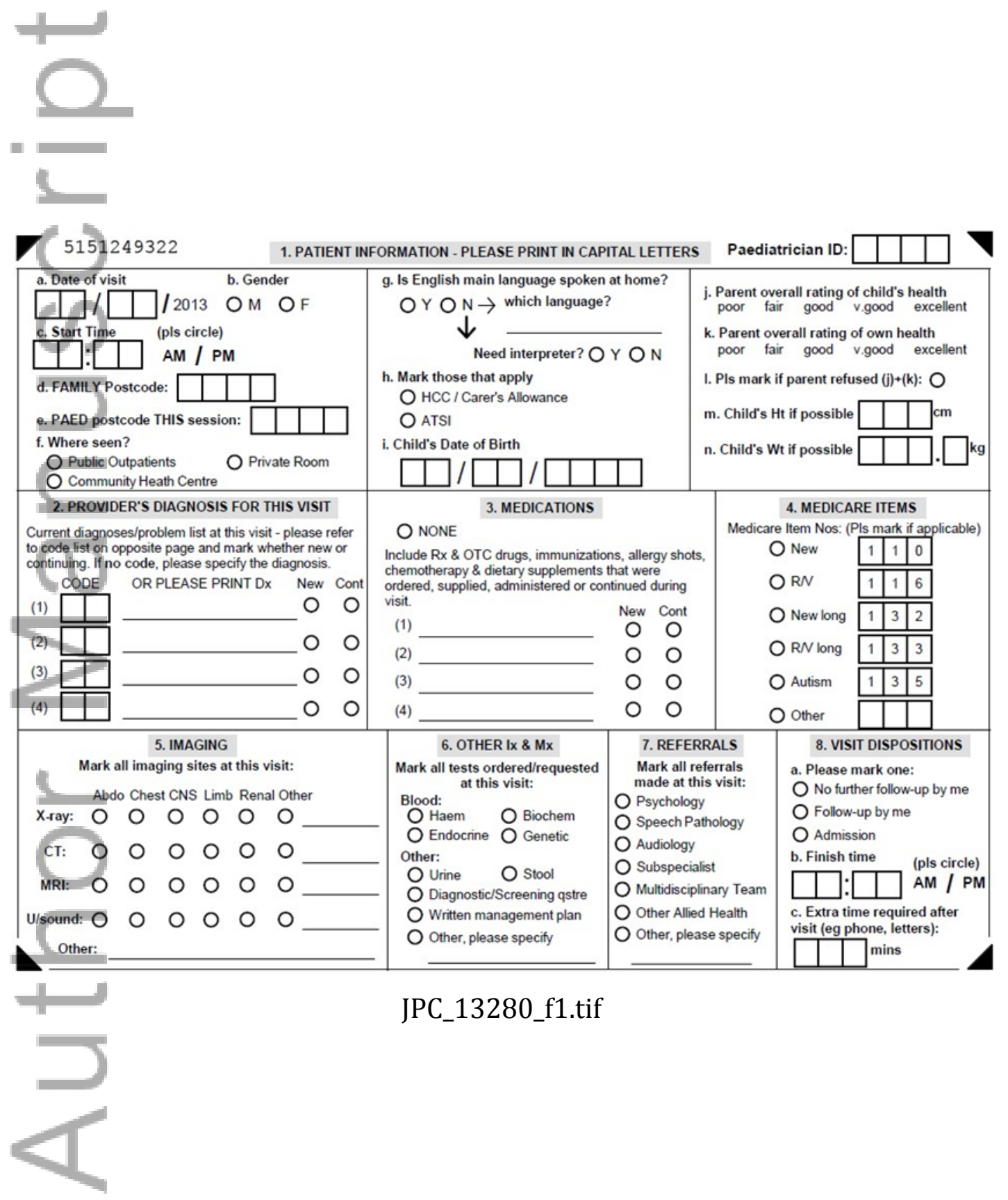

This article is protected by copyright. All rights reserved. 